\title{
Combined epidural morphine and bupivacaine in the treatment of lumbosacral radicular neuropathic pain: a noncontrolled prospective
} study

\author{
This article was published in the following Dove Press journal: \\ Journal of Pain Research \\ 21 November 2016 \\ Number of times this article has been viewed
}

\author{
Simone Vigneri ${ }^{1,2}$ \\ Gianfranco Sindaco 2 \\ Marco La Grua ${ }^{2}$ \\ Matteo Zanella ${ }^{2}$ \\ Laura Ravaioli ${ }^{2}$ \\ Valentina Paci ${ }^{2}$ \\ Gilberto Pari² \\ 'Department of Experimental \\ Biomedicine and Clinical \\ Neurosciences, University of Palermo, \\ Palermo, ${ }^{2}$ Advanced Algology \\ Research and Pain Medicine Unit, \\ Santa Maria Maddalena Hospital, \\ Occhiobello, RO, Italy
}

\begin{abstract}
Objective: The aim of this study was to investigate the therapeutic effectiveness of epidural morphine and bupivacaine in patients with chronic lumbosacral radicular neuropathic pain after the cessation of treatment.

Methods: Twenty-two patients with chronic lumbosacral pain with neuropathic features were enrolled. An indwelling catheter was placed into the epidural space, and each patient received an epidural injection of morphine chlorhydrate and bupivacaine up to three times a day. The medication was administered for 4 weeks. The pain intensity score on a $0-10$ numeric rating scale (NRS), the total pain rating index rank (PRIr-T), and its coefficients were evaluated before treatment and 1 month after catheter removal. $P$-value $<0.05$ was considered statistically significant. Results: NRS and PRIr-T were significantly reduced at follow-up $(P=0.001$ and $P=0.03$, respectively), whereas the parallel evolution of the two scores $(\rho=0.75$ and $P<0.001$, respectively) confirmed significant pain relief lasting up to 1 month after treatment cessation. None of the four pain rating coefficients was significantly modified compared to the others in either responders or nonresponders. Successful clinical outcome (pain reduction $>30 \%$ in NRS) was reached and maintained in half of the patients at follow-up. Conclusion: Combined epidural morphine and bupivacaine seems to be effective in the treatment of neuropathic pain
\end{abstract}

Keywords: epidural, opioids, bupivacaine, neuropathic pain, chronic pain

\section{Introduction}

Lumbosacral radicular pain is a common and disabling condition in adults with pathology of the bones in the distal spine, and it represents a significant quality-of-life issue. ${ }^{1}$ Lower back pain is not always associated with radicular symptoms. Clinical findings of neuropathy may vary significantly, depending on the pathogenesis of the pain symptoms. Neuropathic pain is still a "dark zone" for neuroscientists and treatment remains challenging for clinicians. It has been described as a direct consequence of involvement of the somatosensory system, with a population prevalence between 7 and $10 \%$, thus stressing the importance of a standardized approach for its recognition. ${ }^{2}$ Pharmacological therapies have often proved ineffective, surgery has poorly characterized indications, and the use of interventional neuromodulation (eg, pulsed radiofrequency and spinal cord stimulation) is still debated or not always applicable. ${ }^{3}$ Some older studies reported that opioids have poor efficacy for neuropathic pain, although this conclusion has been progressively questioned because of the lack of compelling
Correspondence: Simone Vigneri Advanced Algology Research and Pain Medicine Unit, Santa Maria Maddalena Hospital, Via Gorizia 2, 45030

Occhiobello, RO, Italy

Tel +39042576 8400

$\mathrm{Fax}+390425768460$

Email simone.vigneri@gmail.com 
evidence, and several reports arguing that a substantial proportion of patients with neuropathic pain might significantly respond to opioids. ${ }^{4}$ Some investigators have evaluated the additional efficacy of local anesthetics, stressing evidence for the development of synergistic effects after coadministration with opioids, and found that bupivacaine and morphine together showed better results than either alone, in terms of patient satisfaction, medication intake, and pain clinic admissions..$^{5}$ Different routes of administration have been tested, and epidural and intrathecal drug delivery confers benefits in comparison with other routes. For instance, these routes avoid first-pass metabolism and the blood-brain barrier and allow the use of lower doses at comparable efficacy, given that the medications are deposited directly at the spinal cord. ${ }^{6-8}$ Considering that epidural administration can be maintained for longer periods with lower risks relative to the intrathecal route, it may be possible to utilize other analgesics to obtain adequate analgesia for prolonged periods.

To the best of our knowledge, no previous study has assessed how epidural therapy with combined opioids and local anesthetics might provide long-lasting pain modulation. The aim of this study was to investigate the effectiveness of epidural morphine and bupivacaine in patients with chronic neuropathic pain associated with lumbosacral radiculopathy.

\section{Methods}

\section{Study design}

The research protocol was approved by the Institutional Review Board committee of the Santa Maria Maddalena Hospital, Occhiobello (RO), Italy. Informed consent was obtained from each patient, and the patients enrolled in the research were allowed to withdraw from the study at any point if they wished.

Prior to the enrollment, every patient was evaluated to confirm probable or definite neuropathic involvement. ${ }^{9}$ The following criteria were adopted as inclusion criteria for the study subjects:

1. Severe pain intensity assessed with a numeric rating scale (NRS) score of $\geq 7 / 10$.

2. Definite or probable neuropathic involvement as assessed by clinical examination and grading system.

3. Chronic lower extremity radicular pain lasting for $>6$ months.

4. Clinical examination suggestive of radicular pain with $\geq 1$ positive provocation tests (eg, straight leg raise test).
5. Poor response to pharmacological therapy, physical therapy, or epidural injection of anti-inflammatories (ie, pain reduction in NRS $\leq 30 \%$ during the 6 months before enrollment).

6. Magnetic resonance imaging and/or electromyographic test suggestive of radiculopathy.

The following exclusion criteria were applied:

1. Possible or unlikely neuropathic pain.

2. Positive response to previous treatments.

3. Comorbid neurological or psychiatric disorders.

4. Significant motor deficits.

The procedure was performed in a suitable operating room, with disinfection and sterilization of all devices. A sterile operative field was maintained while each patient was lying on a fluoroscopy table in the prone position for needle introduction. After injection of local anesthetic to numb the operative zone, a 16-G hollow needle was inserted through the paramedian tissues at a $40^{\circ}$ angle, with the skin and epidural space located by standard loss of resistance to air techniques. An epidural catheter was inserted at the T12-L1 intervertebral space, with the correct placement verified by fluoroscopy. The position of the catheter tip was confirmed by injection of X-ray contrast medium (Iopamiro 300; Bracco Imaging, S.p.A., Milan, Italy) and screening with an image intensifier. A single bolus test with lidocaine $2 \%$ was performed to rule out intrathecal placement. The catheter was tunneled for $5 \mathrm{~cm}$ subcutaneously and then fixed at $10 \mathrm{~cm}$ in the abdominal skin, and the patient was transported to the recovery room (Figure 1).

On the following day, each patient received an epidural analgesic injection followed by a $2 \mathrm{~mL}$ flush with normal saline. The injection solution was composed of morphine chlorhydrate $(0.1 \mathrm{mg} / \mathrm{mL})$ and bupivacaine $(1 \mathrm{mg} / \mathrm{mL})$, and the dose was progressively increased to $3 \mathrm{~mL}$ three times a

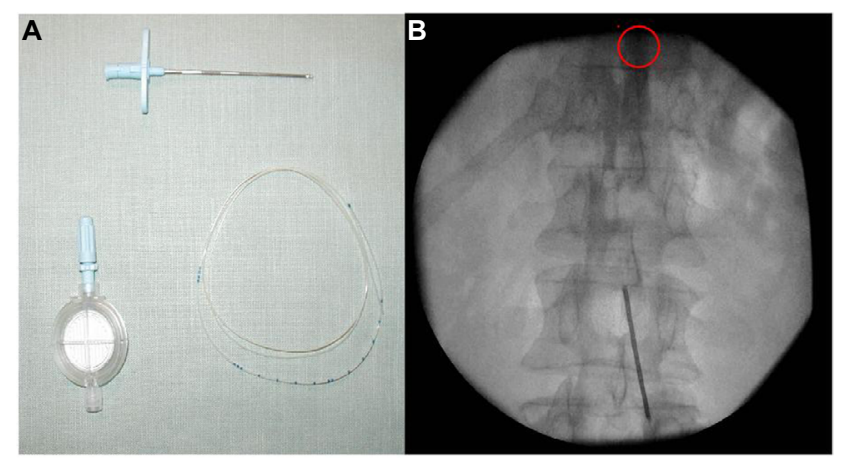

Figure I Extra procedural (A) and intraprocedural (B) features of epidural catheter (the tip circled in red). 
day (total dosage per day: morphine $0.9 \mathrm{mg}$ and bupivacaine $9 \mathrm{mg}$ ). A variable ratio of the opioid and local anesthetic agents was used, such that the dosages of the two drugs were adjusted in order to obtain the optimal analgesia with the fewest side effects in comparison to the postoperative pain treatment (ie, morphine $2-4 \mathrm{mg}$ /day and bupivacaine $0.125 \%) .{ }^{10}$ The medication was administered in the hospital for the first week and self-administered by the patient in the outpatient setting for the following 3 weeks. Proper medication intake and catheter functioning were evaluated every week by an expert nurse and a pain physician. On the 30th day, the catheter was removed and an appointment for clinical follow-up in 1 month was scheduled. No epidural medication adjustments were made during the epidural treatment or after catheter removal. Patient demographics and clinical features are summarized in Table 1.

\section{Outcome measures}

Each patient was evaluated for pain levels by two independent reviewers not involved with catheter placement and drug administration, before catheter placement and at 1 month after removal. Pain intensity was assessed with the 0-10 NRS and by the Italian version of the McGill Pain Questionnaire (QUID), which has 42 descriptors divided into four main pain rating index ranks (sensory, affective, evaluative, and mixed). The total PRIr (PRIr-T) value, given by the sum of all the rank values, describes and quantifies the pain. ${ }^{11,12}$ Response to treatment was considered successful with a pain reduction in NRS $>30 \%$ at follow-up.

\section{Statistical analysis}

The Wilcoxon's rank sum test was applied to evaluate changes in NRS and PRIr-T, comparing baseline and follow-up levels. Moreover, differences between the four PRIr coefficients describing sensory (PRIrc-S), affective

Table I Distribution by age and sex and main clinical features

\begin{tabular}{ll}
\hline Variables & $\mathbf{N}=\mathbf{2 2}$ \\
\hline Age (years) & 61.1 (14.7) \\
Males & 8 \\
Females & 14 \\
Etiopathology & \\
Disk herniation & 9 \\
Failed back surgery syndrome & 13 \\
Radicular levels & \\
L2 & 2 \\
L3 & 3 \\
L4 & 12 \\
L5 & 18 \\
S1 & 8 \\
\hline
\end{tabular}

Note: Data are represented as mean (SD) or $\mathrm{n}$.
(PRIrc-A), evaluative (PRIrc-E), and mixed (PRIrc-M) aspects of pain were compared in the responders and nonresponders. The association between pain variation in NRS and QUID at the follow-up was calculated using the Spearman's test. The Kolmogorov-Smirnov test was used to assess gender differences in NRS before and after treatment. The sample size was chosen in order to obtain a pain reduction $>30 \%$ at follow-up in patients with a pretreatment NRS pain intensity $\geq 7 / 10$. Considering an alpha level of $<5 \%$, a study group of 20 patients allowed achievement of a statistical significance of $>95 \%$ with statistical power of $>80 \%$.

\section{Results}

No significant posttreatment adverse effects or complications occurred. Eighty-three consecutive patients, diagnosed with radicular lumbosacral pain between January 2014 and December 2015, were evaluated in the Pain Medicine Unit of Santa Maria Maddalena Hospital. Oral medications that were prescribed for therapy before the enrollment included non-steroidal anti-inflammatory drugs, antidepressants, anticonvulsants, and opioids, and the pre-enrollment physical therapy was based on a progressive specific exercise program involving the training of the deep abdominal and lumbar muscles. Radicular epidural injection with triamcinolone $40 \mathrm{mg} / \mathrm{mL}$ and lidocaine $2 \% 0.3 \mathrm{~mL}$ was performed with ultrasound guidance. ${ }^{13,14}$ Fifty-three patients did not meet inclusion criteria and were excluded from the study. Two patients were excluded during the treatment period after malfunction and subsequent removal of the epidural catheter, and six patients reported no improvement in pain level at the fourth week and were removed from follow-up. Ultimately, 22 patients remained enrolled in the study, and most (73\%) of these patients reached significant pain relief during treatment. The study profile and the epidural treatment effect on pain scores are summarized in Figure 2 and Table 2, respectively.

NRS and PRIr-T were significantly reduced at follow-up ( $P=0.001$ and $P=0.03$, respectively). These data were confirmed by the parallel evolution in the two scores $(\rho=0.75$, $P<0.001$ ), strengthening marked pain relief lasting up to 1 month after treatment cessation (Figure 3 ). If the four pain rating coefficients were analyzed, none of the single items was significantly modified compared to the others either in responders or in nonresponders. The Oswestry Disability Index was applied for clinical purposes and showed an overall improvement at follow-up. Nevertheless, considering the frequent association with low back pain, disability caused by axial pain might not be accurately discriminated from the 


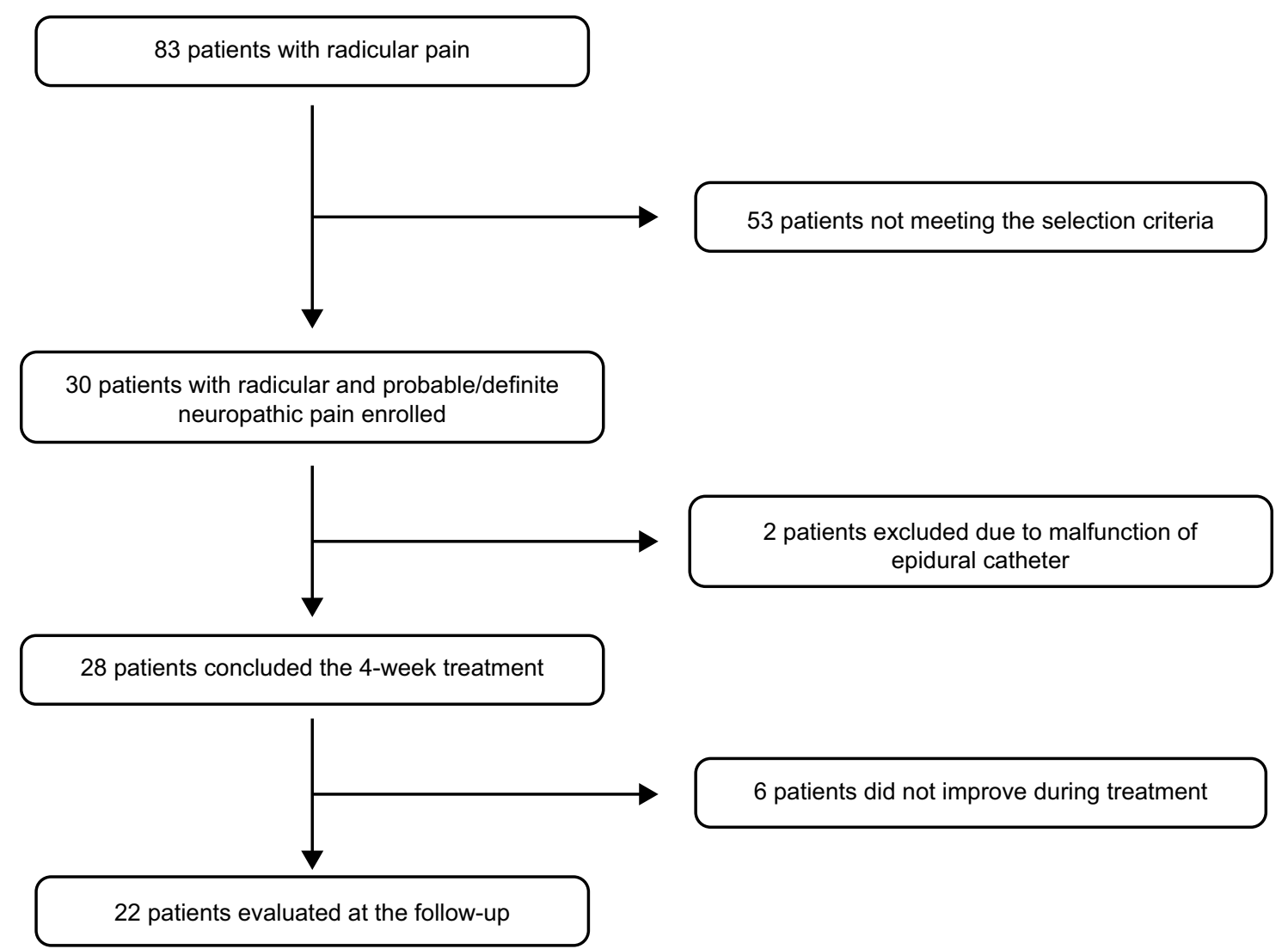

Figure 2 Study profile.

Table 2 Pain variations following epidural treatment with morphine/bupivacaine

\begin{tabular}{lll}
\hline Pain evaluation tool & Pretreatment & Follow-up \\
\hline NRS & $8.5(1.2)$ & $5.6(3.3)$ \\
PRIr-T & $24.5(8.8)$ & $18.3(11.9)$ \\
PRIr-somatic & $0.32(0.07)$ & $0.21(0.14)$ \\
PRIr-affective & $0.34(0.23)$ & $0.21(0.17)$ \\
PRIr-evaluative & $0.37(0.20)$ & $0.23(0.18)$ \\
PRIr-mixed & $0.30(0.21)$ & $0.17(0.21)$ \\
\hline
\end{tabular}

Note: Data are represented as mean (SD).

Abbreviations: NRS, numeric rating scale; PRIr, pain rating index rank; PRIr-T, total PRIr.

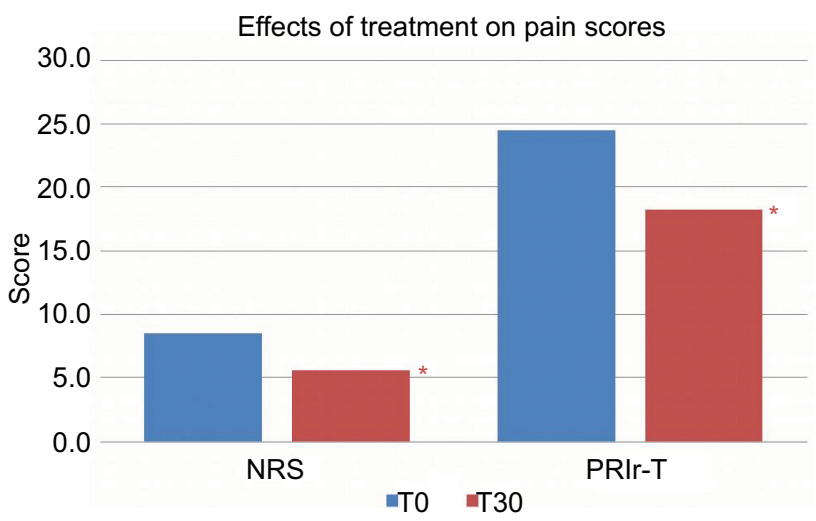

Figure 3 Mean NRS and PRIr-T at pretreatment and 30 days after catheter removal. Note: *Statistical significance in comparison with baseline (NRS, $P=0.00 \mathrm{I}$ and PRIr-T, $P=0.03)$.

Abbreviations: NRS, numeric rating scale; PRIr-T, total pain rating index rank. radiating neuropathic component. Therefore, we chose not to include this index in the study due to the complex nature of lumbosacral radicular pain.

A successful clinical outcome was observed in eleven of the 22 patients at the follow-up, with $50.4 \%$ of effect size and $97.2 \%$ of statistical power. The interaction between gender and pain relief was not statistically meaningful.

\section{Discussion}

In this study, we evaluated pain improvement after the cessation of epidural treatment with morphine and bupivacaine. At follow-up, half of the patients suffering from moderate-tosevere pain at baseline reported a significant improvement, which was confirmed with two validated scores, affecting the sensory and evaluative as much as affective aspects of pain. To our knowledge, this is the first study to report the effectiveness of epidural treatment with combined opioids and anesthetics persisting after catheter removal. If pain improvement had occurred, it was maintained for 1 month after therapy cessation, thereby suggesting a potential role for modifying the natural history of the disease. Although the protocol was complex, involving hospital admission, placement of epidural catheter in the operating room, and the administration of medications for 4 weeks, all the patients 
included in the study had severe chronic pain that was refractory to several standard treatments.

Opioid infusion has increasingly been used as a treatment in noncancer pain and more recently has been assessed in patients with chronic pain. Pain levels improve significantly with higher doses, but these levels can promote the risk of abuse and often burden the patient with adverse effects. One of the main pitfalls in opioid therapy lies in the progressive development of tolerance, which is responsible for decreasing efficacy. ${ }^{15}$ Epidural delivery of anesthetics may be associated with prolonged analgesia and reduced mechanical allodynia in rats with nerve injury, whereas similar effects have also been described in humans with neuropathic pain after lidocaine administration. ${ }^{16}$ In other trials, the combination of intrathecal bupivacaine and morphine showed good efficacy in most cancer and nonmalignant pain patients with neuropathic or mixed pain. In addition to enhancing analgesia, bupivacaine combinations seem to be responsible for opioid-sparing regimens with diminished adverse effects. ${ }^{17}$

Opioids are usually claimed to target dorsal horn cell receptors and cause pre- and postsynaptic modulation of pain, although peripheral effects have also been taken into account due to the identification of opioid receptors on peripheral sensory neuron processes. ${ }^{18}$ A previous study has also shown that microinjection of opioids into the brainstem may elicit powerful antinociceptive effect in animals and humans, likely involving the periaqueductal gray (PAG) and the rostro-ventromedial medulla (RVM). ${ }^{19}$ Although the cellular mechanisms and sites of action are still debated, many local anesthetics block ion channels at the dorsal entry root zone and antagonize pain transmission via $\mathrm{A} \delta$ and $\mathrm{C}$ fibers. ${ }^{20}$ Moreover, bupivacaine may inhibit spinal glutamatergic transmission, and its analgesic effect might also be subsequent to the modulation of N-methyl-D-aspartate receptors in the superficial dorsal horn. ${ }^{21}$

Compelling evidence suggests that ectopic neural discharge may represent an underlying mechanism of neuropathic pain. These abnormal impulses may arise at the site of nerve injury or far from it, in apparently intact axons or structures, driven by abnormal discharges in $\mathrm{A} \beta$ or $\mathrm{C}$ fibers. ${ }^{22}$ In this regard, the role of the dorsal root ganglion (DRG) has been widely investigated, due to its location as a border area between spinal cord and peripheral nerves. Abnormal discharges in the DRG tend to be more sensitive to lidocaine injection than those at the site of nerve injury. Several studies highlighted that hyperexcitable DRG neurons begin to show ongoing activity that lasts many days or weeks after nerve injury. In turn, this pathological activity might induce reversible central sensitization. ${ }^{23}$ In experimental models, systemic lidocaine silences the DRG ectopic discharges without blocking nerve conduction, whereas local anesthetic agents applied intrathecally and to the DRG surface in patients with phantom limb pain produce transient improvement of painful and nonpainful sensations in the majority of subjects, strengthening the conclusion that lidocaine can antagonize spontaneous bursting action potential discharge and sensitization. ${ }^{24}$ Despite the distance from the catheter tip, sensitized DRG might therefore have responded to low-dose bupivacaine and, because of a lack of efficient neurovascular barriers, it could be considered as a potential target in our study.

In addition, ion channels are widely expressed in the central nervous system as much as in the periphery. The number of sodium channels ( $\mathrm{eg}, \mathrm{Na}_{\mathrm{v}} 1.3$ ) has been found to be increased in dorsal horn and thalamic neurons after traumatic spinal cord injury, producing central pain. Blocking the expression of such channels may reverse the excitability changes in either the central nervous system or the peripheral nervous system, whereas injection of lidocaine into the RVM blocks tactile and thermal hyperesthesia. ${ }^{25}$

Increasing evidence is also documenting the antiinflammatory properties of anesthetics, resulting from their modulating action on the immune system. Manchikanti et $\mathrm{al}^{26}$ showed comparable long-lasting efficacy of epidural steroids and anesthetics in patients suffering from chronic lumbar disk herniation. This result might explain the improvement in lowback pain with radicular involvement, which often combines mixed features of nociceptive and neuropathic effects.

How can we explain the maintenance of pain control efficacy in our results, lasting up to 1 month after the cessation of treatment and catheter removal? Several experiments showed that administration of systemic or local anesthetics may improve symptoms related to neuropathic pain for variable amounts of time after the end of therapy. ${ }^{27}$ Some data stress the important role of bupivacaine in pain control: 1) the common tendency to increase the dose of opioids to optimize pain control, whereas in our study, it was maintained at a constant dose, and 2) the reported pain improvement after the addition of intrathecal bupivacaine in patients unresponsive to opioid alone. ${ }^{28}$ Bupivacaine may enhance the analgesic effect of opioids through its action on voltage-gated calcium channels, changing opioid pharmacokinetics and receptor conformation. ${ }^{29}$ Moreover, chronic pain has been associated with structural and functional changes in the human cortex and with dysfunctional descending pain modulation, which may be affected by medications and pain resolution, suggesting 
cortical plasticity processes. ${ }^{30}$ Epidural addition of bupivacaine to opioids might help in restoring physiological antinociceptive mechanisms, therefore preventing or antagonizing chronic neuropathic pain. ${ }^{31}$ Because our patients were suffering from refractory neuropathic pain, we considered a reduction of pain $>30 \%$ (at follow-up) as utilized in clinical trials, as significant. ${ }^{32}$

The analysis of QUID coefficients failed to disclose significant pain variation among PRIrc-S, PRIrc-A, PRIrcE, and PRIrc-M. The treatment improved sensory pain as much as affective quality of pain in responders, whereas none of these items changed compared to the others in poor responders. Nevertheless, the use of pain coefficients is not sufficient to rule out placebo effects, which may play an important role in the subjective response to treatments. ${ }^{33}$ The heterogeneous and small number of patients may be another issue, given that neuropathic pain may develop from different disorders and etiologies, making tighter criteria too restrictive. Nevertheless, we believe that the statistical power in this study was strong enough to support reliable results. Finally, the short duration of follow-up in this study does not allow us to comment on the potential for long-term pain relief. In animal models, intravenous infusion of lidocaine was able to eliminate mechanical allodynia for at least 3 weeks after treatment, but the maximal duration in humans needs to be elucidated in further studies.

\section{Conclusion}

The present results showed significant efficacy of combined epidural morphine and bupivacaine in the treatment of radicular neuropathic pain, which was maintained for up to 1 month after the end of administration. As a result of multiple pathophysiological events, central and peripheral neural changes may produce clinical symptoms and lead to chronic pain. Neuronal sodium-channel blockade over long periods might help restore the normal balance. Maintaining significant pain relief with low doses of epidural bupivacaine/ opioid may allow the physician to minimize adverse effects, neurotoxicity, and drug dosages, or to adopt more conservative approaches (eg, physical therapy) in pain management. Therefore, further studies are needed to evaluate the safety and reliability of this regimen over long periods, to promote the use of epidural treatment in selected cases, or ultimately to develop new implantable pump systems engineered to provide infusions for extended pain relief.

\section{Acknowledgment}

This research project was financially supported by the nonprofit Advanced Algology Research association.

\section{Disclosure}

The authors report no conflicts of interest in this work.

\section{References}

1. Van Boxem K, Cheng J, Patijn J, et al. Lumbosacral radicular pain. Pain Pract. 2010;10(4):339-358.

2. Van Hecke O, Austin SK, Khan RA, Smith BH, Torrance N. Neuropathic pain in the general population: a systematic review of epidemiological studies. Pain. 2014;155(4):1907.

3. Manchikanti L, Abdi S, Atluri S, et al. An update of comprehensive evidence-based guidelines for interventional techniques in chronic spinal pain. Part II: guidance and recommendations. Pain Physician. 2013;16(2 Suppl):S49-S283.

4. McNicol ED, Midbari A, Eisenberg E. Opioids for neuropathic pain. Cochrane Database Syst Rev. 2013;8:CD006146.

5. Deer TR, Caraway DL, Kim CK, Dempsey CD, Stewart CD, McNeil KF. Clinical experience with intrathecal bupivacaine in combination with opioid for the treatment of chronic pain related to failed back surgery syndrome and metastatic cancer pain of the spine. Spine $J$. 2002;2(4):274-278.

6. Osenbach R. Intrathecal drug delivery in the management of pain. In: Fishman S, editor. Bonica's Management of Pain. 4th ed. Philladelphia, PA: Lippincott Williams and Wilkins; 2010:1437-1458.

7. Dellemijn PL, Vanneste JA. Randomised double-blind active-placebocontrolled crossover trial of intravenous fentanyl in neuropathic pain. Lancet. 1997;349(9054):753-758.

8. Roberts LJ, Finch PM, Goucke CR, Price LM. Outcome of intrathecal opioids in chronic non-cancer pain. Eur J Pain. 2001;5(4):353-361.

9. Treede RD, Jensen TS, Campbell JN, et al. Neuropathic pain: redefinition and a grading system for clinical and research purposes. Neurology. 2008;70(18):1630-1635.

10. Ozalp G, Güner F, Kuru N, Kadiogullari N. Postoperative patientcontrolled epidural analgesia with opioid bupivacaine mixtures. Can $J$ Anaesth. 1998;45(10):938-942.

11. Farrar JT, Young JP Jr, LaMoreaux L, Werth JL, Poole RM. Clinical importance of changes in chronic pain intensity measured on an 11-point numerical rating scale. Pain. 2001;94(2):149-158.

12. De Benedettis G, Massel R, Nobili R, Pieri A. The Italian pain questionnaire. Pain. 1988;33(1):53-62.

13. O'Sullivan PB, Phyty GD, Twomey LT, Allison GT. Evaluation of specific stabilizing exercise in the treatment of chronic low back pain withradiologic diagnosis of spondylolysis or spondylolisthesis. Spine (Phila Pa 1976). 1997;22(24):2959-2967.

14. Stanczak J, Blankenbaker DG, De Smet AA, Fine J. Efficacy of epidural injections of Kenalog and Celestone in the treatment of lower back pain. AJR Am J Roentgenol. 2003;181(5):1255-1258.

15. Hassenbusch SJ, Stanton-Hicks M, Covington EC, Walsh JG, Guthrey DS. Long-term intraspinal infusions of opioids in the treatment of neuropathic pain. J Pain Symptom Manage. 1995;10(7):527-543.

16. Hutson P, Backonja M, Knurr H. Intravenous lidocaine for neuropathic pain: a retrospective analysis of tolerability and efficacy. Pain Med. 2015;16(3):531-536.

17. Krames ES, Lanning RM. Intrathecal infusional analgesia for nonmalignant pain: analgesic efficacy of intrathecal opioid with or without bupivacaine. J Pain Symptom Manage. 1993;8(8):539-548.

18. Stein C, Schäfer M, Machelska H. Attacking pain at its source: new perspectives on opioids. Nat Med. 2003;9(8):1003-1008.

19. Tsou K, Jang CS. Studies on the site of analgesic action of morphine by intracerebral microinjection. Sci Sin. 1964;13:1099-1109.

20. Veizi IE, Hayek SM, Narouze S, Pope JE, Mekhail N. Combination of intrathecal opioids with bupivacaine attenuates opioid dose escalation in chronic noncancer pain patients. Pain Med. 2011;12(10):1481-1489.

21. Furutani K, Ikoma M, Ishii H, Baba H, Kohno T. Bupivacaine inhibits glutamatergic transmission in spinal dorsal horn neurons. Anesthesiology. 2010;112(1):138-143. 
22. Devor M, Seltzer Z. Pathophysiology of damaged nerves in relation to chronic pain. In: Wall PD, Melzack R, editors. Textbook of Pain. London, UK: Churchill-Livingstone; 1999:129-164.

23. Chung JM, Chung K. Importance of hyperexcitability of DRG neurons in neuropathic pain. Pain Pract. 2002;2(2):87-97.

24. Vaso A, Adahan HM, Gjika A, et al. Peripheral nervous system origin of phantom limb pain. Pain. 2014;155(10):1384-1391.

25. Hains BC, Klein JP, Saab CY, Craner MJ, Black JA, Waxman SG. Upregulation of sodium channel Nav1.3 and functional involvement in neuronal hyperexcitability associated with central neuropathic pain after spinal cord injury. J Neurosci. 2003;23(26):8881-8892.

26. Manchikanti L, Cash KA, Pampati V, Falco FJ. Transforaminal epidural injections in chronic lumbar disc herniation: a randomized, double-blind, active-control trial. Pain Physician. 2014;17(4):E489-E501.

27. Chaplan SR, Bach FW, Shafer SL, Yaksh TL. Prolonged alleviation of tactile allodynia by intravenous lidocaine in neuropathic rats. Anesthesiology. 1995;83(4):775-785.
28. Kumar K, Bodani V, Bishop S, Tracey S. Use of intrathecal bupivacaine in refractory chronic nonmalignant pain. Pain Med. 2009;10(5): 819-828.

29. Maves TJ, Gebhart GF. Antinociceptive synergy between intrathecal morphine and lidocaine during visceral and somatic nociception in the rat. Anesthesiology. 1992;76(1):91-99.

30. Younger JW, Chu LF, D’Arcy NT, Trott KE, Jastrzab LE, Mackey SC. Prescription opioid analgesics rapidly change the human brain. Pain. 2011;152(8):1803-1810.

31. Ossipov MH, Morimura K, Porreca F. Descending pain modulation and chronification of pain. Curr Opin Support Palliat Care. 2014;8(2): 143-151.

32. Dworkin RH, Turk DC, Wyrwich KW, et al. Interpreting the clinical importance of treatment outcomes in chronic pain clinical trials: IMMPACT recommendations. J Pain. 2008;9(2):105-121.

33. Dobrila-Dintinjana R, Nacinović-Duletić A. Placebo in the treatment of pain. Coll Antropol. 2011;35(Suppl 2):319-323.

\section{Journal of Pain Research}

\section{Publish your work in this journal}

The Journal of Pain Research is an international, peer reviewed, open access, online journal that welcomes laboratory and clinical findings in the fields of pain research and the prevention and management of pain. Original research, reviews, symposium reports, hypothesis formation and commentaries are all considered for publication.

\section{Dovepress}

The manuscript management system is completely online and includes a very quick and fair peer-review system, which is all easy to use. Visit http://www.dovepress.com/testimonials.php to read real quotes from published authors. 